\title{
A DIPLOMÁTICA CONTEMPORÂNEA EM PERIÓDICOS ON-LINE
}

\author{
A CONTEMPORARY DIPLOMACY IN ON-LINE JOURNALS
}

\author{
Fernanda Kieling Pedrazzi ${ }^{1}$ e Eliete Regina Rabaioli Camargo ${ }^{2}$
}

Recebido em: 12/04/2016

Aceito em: 27/09/2016

\section{RESUMO}

Este trabalho apresenta uma análise das revistas on-line com conceito Qualis A e B, identificando o que está sendo produzido na área de Diplomática Contemporânea no Brasil e que vem tendo visibilidade em publicações acadêmicas. Tal objetivo surgiu a partir da constatação da inexistência de conteúdos sobre Diplomática Contemporânea, realizada pelos discentes do curso de Arquivologia da Universidade Federal de Santa Maria (UFSM), Rio Grande do Sul, com base na pesquisa acerca da Avaliação Institucional. A partir disso, o presente estudo identificou as produções nesta área específica, quem são seus autores e se essa realidade de falta de conteúdos sobre Diplomática Contemporânea se estende a outras Universidades no Brasil. Os resultados mostram que o número de publicações on-line na área de Diplomática Contemporânea em periódicos avaliados pela Coordenação de Aperfeiçoamento de Pessoal de Nível Superior (Capes) com Qualis A e B é baixo: das 12 revistas verificadas da área da Ciência da Informação, apenas duas (Qualis B2 e B4) continham artigos sobre a temática (totalizando três artigos). Analisando a grade curricular de formação básica dos autores, verificou-se a inexistência de conteúdos atinentes à Diplomática Contemporânea e identificou-se que outras áreas, além da Arquivologia, estão contribuindo para a produção sobre o tema.

Palavras-chave: Arquivologia; Diplomática Contemporânea; Periódicos on-line; Qualis.

\begin{abstract}
This paper presents an analysis of online magazines with concept Qualis A and B, identifying what is being produced in Contemporary Diplomatic area in Brazil and has had visibility in academic publications. This objective arose from the finding of lack of Contemporary Diplomatic on content, performed by students of Archivology course at the Federal University of Santa Maria (UFSM), Rio Grande do Sul, based on research on the Institutional Assessment. From this, the present study identified the productions in this particular area, who are the authors and if this reality of lack of Contemporary Diplomatic over content extends to other universities in Brazil. The results show that the number of online publications in Contemporary Diplomatic area in journals evaluated by the Higher Education Personnel Improvement Coordination (Capes) with Qualis $A$ and $B$ is low: of the 12 magazines checked the area of Information Science, only two (Qualis B2 and B4) contained articles on the subject (totaling three articles). Analyzing the curriculum of basic training of the authors, it was the lack of content relating to Contemporary Diplomatic and identified other areas, in addition to Archivology, are contributing to the literature on the subject.
\end{abstract}

Keywords: Archival; Contemporary diplomacy; On-line journals; Qualis.

1 Professora Adjunta da Universidade Federal de Santa Maria (UFSM) no Departamento de Documentação do Centro de Ciências Sociais e Humanas (CCSH). Doutora em Letras pela UFSM. Possui graduação em Comunicação Social - Jornalismo pela UFSM, graduação em Arquivologia pela UFSM e mestrado em Engenharia de Produção pela UFSM. E-mail: fernanda.pedrazzi@gmail.com

2 Bacharel em Arquivologia pela Universidade Federal de Santa Maria (UFSM). Mestranda do Programa de Pós-Graduação Profissional em Patrimônio Cultural, pela UFSM. Arquivista da Casa de Memória Edmundo Cardoso. E-mail: elietecamargo15@hotmail.com 


\section{Introdução}

Este trabalho tem como propósito analisar as publicações na área de Diplomática Contemporânea em periódicos da área da Ciência da Informação que estão disponíveis on-line e que tenham sido classificados pela Coordenação de Aperfeiçoamento de Pessoal de Nível Superior (Capes) com conceitos Qualis A ou B, buscando reconhecer o que está sendo produzido na área. ${ }^{3}$ Este objetivo surgiu a partir do Projeto de Avaliação Institucional do Curso de Arquivologia da Universidade Federal de Santa Maria (UFSM), Rio Grande do Sul, que vem sendo realizado desde 2010. Para os discentes, a disciplina de Diplomática tem apresentado problemas em sua grade curricular, pois não contempla conteúdos na área de Diplomática Contemporânea, os quais são fundamentais principalmente pela grande quantidade de documentos eletrônicos produzidos na atualidade.

A partir da pesquisa em revistas on-line da área de Ciência da informação com classificação Qualis A e B, é possível reconhecer quem são os autores, o que estão produzindo na área e a que instituição pertencem. Além disso, pretende-se verificar se a disciplina de Diplomática Contemporânea está incluída na grade curricular das instituições envolvidas nas produções, a fim de compreender se a inexistência dessa disciplina uma problemática presente em outras instituições brasileiras.

Assim, este trabalho tem como objetivo principal proceder a um levantamento sobre a Diplomática Contemporânea no Brasil a partir da análise das publicações em periódicos com classificação Qualis A e B. Além desse objetivo geral, foram estabelecidos os seguintes objetivos específicos: realizar um levantamento das revistas científicas on-line com alto nível de classificação Qualis que contenham artigos sobre Diplomática Contem-

3 Este estudo é resultado da pesquisa realizada em 2013 na disciplina de "Trabalho de Conclusão de Curso", pertencente ao Curso de Arquivologia da Universidade Federal de Santa Maria (UFSM). porânea; identificar o ano das publicações, quem são os autores, bem como as instituições de ensino à que pertencem; $\mathrm{e}$ analisar a grade curricular dos cursos de Arquivologia no Brasil frequentados pelos autores com publicações na área, a fim de verificar a existência da disciplina de Diplomática Contemporânea.

Este estudo irá contribuir para identificação do status da produção acadêmica das instituições de ensino superior sobre o tema. Ademais, poderá incentivar novos estudos na área pelo fato de trazer um levantamento bibliográfico acerca da temática.

\section{Referencial teórico}

A seguir, são abordados os principais tópicos relacionados à área de Arquivologia que fornecerão a base teórica para o desenvolvimento deste estudo sobre Diplomática Contemporânea.

\subsection{Curso de Arquivologia de Santa Maria, Rio Grande do Sul}

Hoje a maioria dos cursos de Arquivologia no Brasil se concentra nas regiões Sul e Sudeste. A região Sul abrange cinco cursos, e entre estes está o curso de Arquivologia da UFSM, que foi criado pelo Conselho de Ensino, Pesquisa e Extensão (CEPE) a partir do Parecer n. ${ }^{\circ}$ 179/1976. Pela Portaria n. ${ }^{\circ}$ 076/1981 do Ministério da Educação e Cultura (MEC), o curso passou a ser vinculado ao Centro de Ciências Sociais e Humanas (CCSH).

O curso de Arquivologia foi criado em Santa Maria devido ao crescimento e desenvolvimento socioeconômico e cultural que exigia um controle maior das atividades administrativas da região. Havia uma escassez de pessoas qualificadas no mercado, acompanhada da falta de experiência ou conhecimentos arquivísticos. O curso teve início com a colaboração de professores de áreas afins tanto da UFSM quanto de outras instituições. 
O currículo vigente em 2013 foi aprovado desde o ano de 2004. No ano de 2011, foi criado um projeto denominado "A revisão curricular como meio de avaliação do ensino de Arquivologia na UFSM" e registrado no Gabinete de Estudos e Apoio Institucional (GEAIC), sob o número 029700 (GEAIC/UFSM), que teve como resultado sugestões dos acadêmicos sobre "outros conhecimentos da área a serem incluídos na grade curricular do Curso". Constante et al (2012, p. 6) registraram, em publicação, a informação de que, como resposta, a maioria dos alunos citou, entre outras demandas, a necessidade de incluir conteúdos de Diplomática Contemporânea no programa da disciplina de Diplomática ou de criar uma nova disciplina sobre o tema.

Em 2012, trabalhou-se com um projeto denominado "Revisão curricular como meio de avaliação do ensino de Arquivologia na UFSM: um novo diálogo". Em uma reunião com os alunos para a discussão de sugestões, ficou evidenciada a necessidade de adequar a ementa da disciplina de Diplomática existente no currículo do Curso de Arquivologia (PPC, 2004), incluindo material sobre Diplomática Contemporânea, e de utilizar o laboratório de informática nas aulas (Constante et al, 2012a, p. 9).

Desde 2008, o curso fornece aos graduados a perspectiva de realizar uma pós-graduação, pois é oferecida uma especialização na área de Gestão em Arquivos, na modalidade de educação a distância por meio do Sistema Universidade Aberta do Brasil (UAB) na própria UFSM, sendo ofertadas vagas para alunos de diferentes cidades dos mais diversos estados brasileiros. Além da especialização, o acadêmico ainda tem a possibilidade de continuar seus estudos no Mestrado Profissional em Patrimônio Cultural nas áreas de Arquitetura, Arquivologia, História, Engenharia Civil, Paleontologia, Arqueologia e Museologia. Na área de Arquivologia, o mestrado abarca a linha de pesquisa e Patrimônio Documental Arquivístico. Com essa estrutura de ensino de graduação e pós-graduação, o curso busca uma educação continuada em projetos e pesquisas na área arquivística, para que cada vez mais o pesquisador e estudante da área tenham uma qualificação melhorada, ampliando seus conhecimentos.

\subsubsection{Diplomática Contemporânea}

O profissional de Arquivologia está sempre em transformação. No início, esse profissional era responsável somente pela integridade física do documento, embora sua principal função consista em ser responsável pelas informações contidas nesta documentação com o objetivo de torná-las acessíveis ao público e de atualizá-las constantemente conforme o avanço da tecnologia.

Para Lúcia Nascimento,

A concepção de Diplomática, enquanto saber, se dá à época da ciência moderna, momento em que se registra a discussão acerca dos elementos constitutivos do documento e de sua natureza; período da elaboração dos fundamentos da análise dos documentos antigos e dos princípios atemporais de abordagem estrutural do documento (NASCIMENTO, 2009, p. 81, grifo do autor).

Dentre as áreas de abrangência da arquivística, a Diplomática, desde os tempos medievais, é responsável pela identificação e análise das informações contidas nos documentos. A mudança significativa da tecnologia fez com que a Diplomática Contemporânea, a partir do século XXI, se tornasse uma ferramenta da Ciência da Informação, possibilitando uma nova forma de verificar a autenticidade dos documentos eletrônicos.

A Diplomática Contemporânea, independente de sua natureza, avalia as informações de diferentes documentos. Com o avanço da tecnologia, a quantidade de documentos produzidos em 
meio digital está crescendo gradativamente, levando, ainda, à transferência do suporte de papel para o digital.

A primeira pessoa a aplicar estudos na área da Diplomática Contemporânea em arquivos públicos foi a italiana Paola Carucci, que define Diplomática Contemporânea como uma disciplina que estuda o documento, bem como o arquivo, o registro e principalmente os aspectos formais que definem a natureza dos atos e efeitos (RODRIGUES, 2012). Tognoli e Guimarães (2009, p. 3 ) relatam que a percursora dos métodos diplomáticos em documentos contemporâneos na América do Norte foi a italiana Luciana Duranti. A arquivista observa que os mesmos métodos de analisar os documentos medievais são utilizados para compreender os documentos contemporâneos. A Diplomática Contemporânea tem seu espaço e ganha força na Escola Espanhola, com a aplicação de métodos diplomáticos contemporâneos em documentos.

Duranti foi responsável por "introduzir no Canadá e Estados Unidos, esta nova abordagem do uso da Diplomática. Contratada pela Universidade da Columbia Britânica, em Vancouver no Canadá para ensinar Diplomática" (RODRIGUES, 2007, p. 178) pela falta de material para repassar aos alunos, ela elaborou seis edições de artigos relacionados ao novo método de análise da Diplomática Contemporânea, aplicando a teoria a qualquer tipo e meio de documento e ocasionando a difusão dos novos métodos. Com a propagação de seus estudos científicos em relação à análise de documentos modernos, Duranti tornou-se "um marco referencial na área, no contexto da arquivística internacional" (RODRIGUES, 2007, p. 178).

A Diplomática Contemporânea atualmente é também conhecida como Diplomática Arquivística. Além de voltar-se à estrutura formal dos documentos, avaliando itens como a autenticidade e veracidade, engloba um estudo mais elaborado voltado para a tipologia documental, o que possibilita conhecer o contexto do documento de forma mais aprofundada. Segundo Guimarães e Tognoli (2009, p. 7), "o papel do método Diplomático é repartir e analisar essa forma, através de seus elementos internos e externos, com objetivo de analisar a gênese documental, sua evolução, tradição e autenticidade".

As disciplinas de Arquivística e Diplomática Contemporânea têm em comum o mesmo objeto de estudo, a tipologia. Segundo Tognoli e Guimarães (2009, p. 6), o estudo da tipologia documental "acabaria por trazer a solução para alguns dos problemas enfrentados pelos arquivistas do século XXI".

Para Viana e Rodrigues (2011, p. 9), a Diplomática Contemporânea "seria capaz de contribuir para o tratamento técnico ao fornecer um método de análise crítica a qualquer tipo documental e não somente ao documento digital".

A Diplomática Contemporânea, além de trabalhar com a autenticidade dos documentos em meio digital, contribui para a análise de outras atividades metodológicas, beneficiando os demais critérios arquivísticos, como a identificação, avaliação e descrição dos documentos.

A Diplomática Contemporânea tem como metodologia específica analisar a gênese documental em documentos eletrônicos, a fim de torná-los fidedignos e passíveis de prova. $\mathrm{O}$ grande desafio encontrado em documentos em formato eletrônico está relacionado ao grau de falsificação da estrutura de um documento digital e à forma como o profissional irá controlar sua proliferação em meio digital, já que o acesso para alteração dos dados está cada vez mais fácil.

\subsection{Capes}

A Capes foi criada em 11 de julho de 1951 pelo Decreto n. ${ }^{\circ} 29.741$, com o objetivo de "assegurar a existência de pessoal especializado em quantidade e qualidade suficientes para atender às ne- 
cessidades dos empreendimentos públicos e privados que visam ao desenvolvimento do país" (DECRETO, 1951). Esse órgão tem um papel importante para a educação superior e expansão de programas de pós-graduação, além de propiciar acesso e divulgação à produção de periódicos científicos. Além disso, possui um sistema de avaliação que serve como instrumento em universidades a fim de contribuir para a padronização de artigos e trabalhos acadêmicos produzidos.

A Capes utiliza o sistema WebQualis, um programa que contém um conjunto de procedimentos que analisa o grau de qualidade da produção intelectual desenvolvida em meio acadêmico. Esse programa foi concebido para realizar a avaliação dos trabalhos a partir de informações que são disponibilizadas no aplicativo do banco de dados, culminando em uma lista de classificação e na divulgação de artigos e outros tipos de produção.

A classificação é realizada por área, sendo atualizada anualmente. Essa avaliação enquadra os trabalhos científicos em níveis de qualidade (A1, A2, B1, B2, B3, B4, B5 e C), sendo A1 o conceito com maior peso e $\mathrm{C}$ o conceito com peso zero. O nível de qualificação é estipulado por cada banca de cada área, e um mesmo trabalho pode ser publicado em diferentes áreas, recebendo diferentes níveis de qualificação ${ }^{4}$.

\subsubsection{Publicação em periódicos cientí-} ficos on-line

$\mathrm{O}$ periódico on-line é uma ferramenta utilizada para a publicação de artigos científicos em meio eletrônico e auxilia na disseminação dos conteúdos, acelerando as pesquisas científicas e proporcionando acesso facilitado aos artigos, bem como troca de conhecimento entre os autores. Segundo Bomfá e Blattmann (s/a, p. 2), "a atividade científica tem como principal elemento a comunicação entre os pares em busca da disseminação da ciência e desenvolvimento de estudos".
Castedo (2007) destaca alguns benefícios que os periódicos on-line propiciam para pesquisas:

Ao publicar um título em meio eletrônico e disponibilizá-lo on-line, nessa fase, os editores científicos procuravam maior rapidez na busca de informação e maior facilidade de acesso, maior agilidade na divulgação dos resultados das pesquisas, chance igualitária de acesso aos cientistas mais dispersos geograficamente, entre outros benefícios (CASTEDO, 2007, p. 3).

A publicação em periódicos científicos on-line é uma forma de divulgar os trabalhos, permitindo à sociedade acessar o que as instituições de ensino estão produzindo e contribuindo para uma maior abrangência das publicações. Tal divulgação depende apenas da disponibilidade de um computador ou outro equipamento com acesso à rede da internet e de uma visita ao Website para que seja possível explorar os inúmeros periódicos que são ofertados na rede. Outra vantagem das publicações on-line é o baixo custo da veiculação em comparação com os periódicos impressos.

Contudo, é preciso gerenciar essas informações. Por esse motivo, as instituições devem fornecer um alto nível de credibilidade quanto à avaliação dos trabalhos para garantir a autenticidade, veracidade e fidelidade das informações fornecidas aos usuários em publicações de periódicos científicos on-line.

\section{Método de pesquisa}

Este estudo pode ser classificado como qualitativo, descritivo e explicativo. Busca analisar, na área das revistas on-line com conceito Qualis A e B, o que está sendo produzido na área de Diplomática Contemporânea no Brasil, descrevendo a grade curricular das instituições de ensino e a formação básica dos autores dos artigos publicados. 


\section{Apresentação e discussão dos resultados}

Para definir as revistas brasileiras on-line na área da Ciência da Informação a serem analisadas, tomou-se como base a lista de revistas presentes no livro "Arquivologia: produções em ensino e pesquisa" (LUNARDELLI, 2013), editado pela Universidade Estatual de Londrina (UEL) (Quadro 1).

Concomitantemente, foi realizada uma pesquisa na base de dados do Sistema Integrado Capes (SICAPES) no Portal Capes, identificando-se aque-

las revistas científicas que apresentavam versões on-line e averiguando se havia produções na área de Diplomática Contemporânea. Das 12 revistas analisadas, somente duas passaram a compor

\begin{tabular}{|l|}
\hline Arquivística.Net \\
\hline Biblos \\
\hline Datagramazero \\
\hline Em Questão \\
\hline Encontros Bibli \\
\hline Informação \& Informação \\
\hline Informação \& Sociedade \\
\hline LIINC em Revista \\
\hline Perspectiva em Ciência da Informação \\
\hline Ponto de Acesso \\
\hline Revista ACB \\
\hline $\begin{array}{l}\text { Revista Brasileira e Documentação e } \\
\text { Transinformação }\end{array}$ \\
\hline Quadro 1 - Revistas da Ciência da Informação
\end{tabular}

Fonte: Lunardelli (2013).

o universo da pesquisa com publicação na área: a revista Arquivística.Net com dois artigos, e a revista Informação \& Informação com apenas uma artigo publicado na área (Quadro 2).

\begin{tabular}{|c|c|}
\hline Revista & Endereço on-line \\
\hline Arquívistica.Net (B4) & http://www.arquivistica.net/ojs/index.php \\
\hline $\begin{array}{c}\text { Informação \& Informação } \\
\text { (B2) }\end{array}$ & http://www.uel.br/revistas/uel/index.php/informacao/index \\
\hline \multicolumn{2}{|c|}{} \\
\hline
\end{tabular}

A partir da análise dos artigos, optou-se por suprimir os nomes dos autores, de modo que somente a informação referente ao grau de formação básica, retirada da página da Plataforma Lattes, foi divulgada. Os dados acerca da grade curricular dos cursos frequentados pelos autores dos artigos analisados foram encontrados nas páginas referentes às respectivas instituições de ensino.

$\mathrm{Na}$ revista Arquívistica.Net, foram publicados dois artigos relacionados à Diplomática Contemporânea. Um deles, denominado "Brevíssimas considerações sobre a busca de uma Ação Comunicativa entre o pensamento de Habermas e a Diplomática Arquivística Contemporânea", foi publicado no ano de 2007. A autora tem formação básica em Arquivologia pela Universidade Federal do Estado do Rio de Janeiro (UNIRIO). Verificando a grade curricular do curso de Arquivologia dessa, percebeuse a inexistência da disciplina de Diplomática Contemporânea.

O outro artigo publicado na revista Arquivística.Net intitula-se "Conjugando Diplomática e XML: aproximação possível no contexto da proveniência de documentos jurídicos digitais" data de 2007 e tem duas autoras, uma com formação básica em Arquivologia e outra em Biblioteconomia pela mesma instituição, a Universidade Estadual de Londrina (UEL). Analisando a grade curricular dos cursos, constatou-se a presença da disciplina de Diplomática Contemporânea no curso de Arquivologia e sua ausência no curso de Biblioteconomia.

Já na revista Informação \& Informação, apenas uma artigo foi publicado: "A organização da informação jurídicodigital e os avanços teóricos da diplomática: uma reflexão acerca da eficácia pro- 
batória". Elaborado por dois autores, um formado em Biblioteconomia pela Universidade Federal Estadual de Paulista "Júlio de Mesquita Filho" (UNESP), e outro formado em Direito pela Fundação de Ensino Eurípides Soares Rocha Marília, foi publicado em 2007. Analisando a grade curricular de ambos os cursos, verificou-se a inexistência da disciplina de Diplomática Contemporânea.

É possível perceber, assim, que o número de publicações em periódicos on-line com conceito Qualis A e B na área de Diplomática Contemporânea é relativamente baixo, uma vez que somente foram encontradas três produções publicadas na área.

Todas as publicações são refe- rentes ao ano de 2007. Apesar de as revistas terem o mesmo conceito, observou-se que a estrutura dos artigos e a qualificação são distintas. Uma dessas diferenças consiste no número de referências utilizadas para a produção do artigo publicado na revista Informação \& Informação, que é superior ao dos demais, além das palavras-chaves, que especificam o detalhamento do tema a ser trabalhado no texto.

O primeiro artigo da Arquivística.Net não contém palavras-chaves $\mathrm{e}$ não possui seções que auxiliem a estruturar o texto nem mesmo um resumo no início do artigo, o que dificulta a identificação do tema a que se destina a publicação (Quadro 3).

\begin{tabular}{|c|c|c|c|}
\hline Revistas & Arquivística.Net & Arquivística.Net & $\begin{array}{c}\text { Informação \& } \\
\text { Informação }\end{array}$ \\
\hline Conceito & $\mathrm{B} 4$ & $\mathrm{~B} 4$ & $\mathrm{~B} 2$ \\
\hline Palavras-chave & 3 & 0 & 4 \\
\hline Número de páginas & 17 & 11 & 16 \\
\hline Estrutura de artigo & $\begin{array}{c}\text { Está estruturado em } \\
\text { seis tópicos }\end{array}$ & $\begin{array}{c}\text { Apresenta apenas o } \\
\text { texto, sem tópicos, } \\
\text { e as referências }\end{array}$ & $\begin{array}{c}\text { Está estruturado em } \\
\text { seis tópicos }\end{array}$ \\
\hline $\begin{array}{c}\text { Número de } \\
\text { referências }\end{array}$ & 11 & 7 & 42 \\
\hline
\end{tabular}

Quadro 3 - Comparação entre os artigos científicos analisados

Analisando a biografia dos autores dos artigos, chamou atenção a presença de outras áreas afins à Arquivologia produzindo sobre o tema: a Biblioteconomia está publicando o mesmo percentual de artigos científicos acerca de Diplomática Contemporânea que a Arquivologia, conforme pode ser visualizado no Gráfico 1.

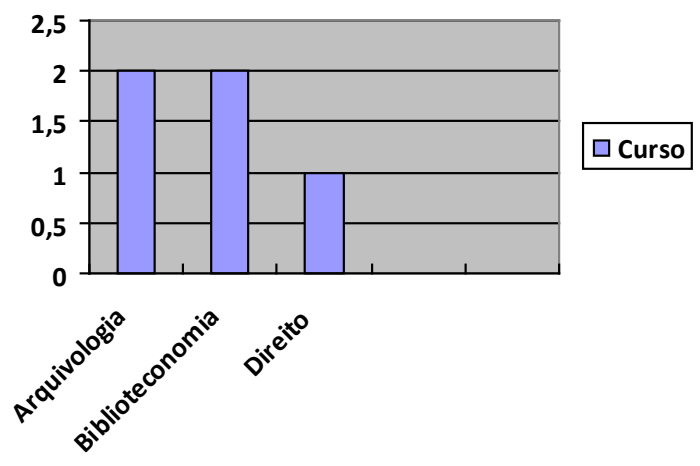

Gráfico 1 - Formação dos autores dos artigos científicos analisados 
$\mathrm{Na}$ antiguidade, arquivos e bibliotecas, por muitos anos, desenvolveram-se juntos, motivo pelo qual algumas características ainda hoje são semelhantes. A Arquivologia e Biblioteconomia são áreas afins, ambas pertencentes à grande área da Ciência da Informação; ademais, algumas disciplinas do curso de Arquivologia são disponibilizadas no curso de Biblioteconomia. Conforme afirmam Richter, Garcia e Penna, essa relação ocorre nos dois sentidos, pois "no currículo acadêmico dos cursos de Biblioteconomia, há disciplinas relacionadas com a Arquivística e viceversa" (1997, p. 60).
Analisando os currículos de cada instituição, verificou-se que a maioria dos autores que produziram na área não cursou durante a graduação a disciplina de Diplomática Contemporânea, a qual não consta na grade curricular dos cursos nem mesmo como disciplina eletiva.

Só o curso de Arquivologia da UEL, no qual um dos autores dos artigos é formado, tem a disciplina em sua grade curricular, como é possível perceber no Quadro 4. Apesar disso, é preciso ressaltar que a presença da disciplina no currículo atual da instituição não assegura que o autor lá formado tenha cursado a disciplina, já que o currículo pode ter sido alterado recentemente.

\begin{tabular}{|c|c|c|}
\hline Curso & $\begin{array}{c}\text { Instituição de Ensino } \\
\text { (Graduação) }\end{array}$ & Diplomática Contemporânea \\
\hline Arquivologia & $\begin{array}{c}\text { Universidade Federal do Estado do } \\
\text { Rio de Janeiro }\end{array}$ & Inexistência da disciplina \\
\hline Biblioteconomia & Universidade Estatual de Londrina & Inexistência da disciplina \\
\hline Arquivologia & Universidade Estatual de Londrina & Presença da disciplina \\
\hline Biblioteconomia & $\begin{array}{c}\text { Universidade Paulista “Júlio de Mes- } \\
\text { quita Filho" - Campus Marília }\end{array}$ & Inexistência da disciplina \\
\hline Direito & $\begin{array}{c}\text { Centro Universitário Eurípides de } \\
\text { Marília }\end{array}$ & Inexistência da disciplina \\
\hline
\end{tabular}

Quadro 4 - Cursos de universidades que ofertam a disciplina de Diplomática Contemporânea

Foi possível identificar, ainda, uma mudança na filiação institucional dos autores ao comparar a data de publicação e a data de realização deste estudo. Dois deles, que não identificaram sua filiação na data da publicação do artigo, atualmente estão trabalhando como professores em instituições estatuais: um atua como professor titular no Departamento de Ciência da Informação da UNESP - Campus Marília, e o outro atua como professor assistente no Departamento de Ciência da Informação da UEL.

Os outros três autores estão atuando em diferentes instituições. Um deles, que atuava na data da publicação do artigo como professor na Universidad
Nacional del Centro de la Provincia de Buenos Aires, hoje leciona na Fundação de Ensino Eurípedes Soares Rocha Marília. Outro, que era aluno de doutorado em Ciência da Informação no Instituto Brasileiro de Informações em Ciência e Tecnologia (IBICT) no momento da publicação, trabalha hoje como arquivista na Fundação Casa de Rui Barbosa (FCRB), ocupando o cargo de servidor público. $\mathrm{E}$ o terceiro autor, que na data da publicação era servidor público municipal, atuando como Técnico de Gestão Pública na Prefeitura Municipal de Londrina, hoje trabalha como Arquivista no cargo de servidor estadual do Ministério Público do Estado do Paraná. 
Pode-se verificar, assim, que pelo menos três dos cinco autores exerciam no período de publicação dos artigos atividades diferentes das atuais. Além disso, dois dos cincos autores trabalham hoje como docentes de universidades públicas (uma federal e outra estadual).

Ao consultar a Plataforma Lattes dos autores que exercem a profissão de professor, percebeu-se que um dos docentes atua na área de análise documental referente à Diplomática, além de trabalhar em áreas relacionadas à Organização da Informação, à Ciência da Informação e à Epistemologia da Ciência da Informação. Já o outro não exerce atividade especificamente na área de Diplomática, mas atua em atividades relacionadas à Tecnologia da Informação, Preservação Digital e Software Livre.

\section{Conclusão}

Com a realização desta pesquisa, pode-se perceber que, apesar do baixo número de instituições de ensino que estão ofertando a disciplina de Diplomática Contemporânea, existem pesquisadores interessados em pesquisar e produzir na área, como é o caso até mesmo de cursos afins à Arquivologia. Falta, contudo, um incentivo para que as instituições de ensino introduzam essa disciplina em sua grade curricular, pois o número de artigos produzidos em revistas on-line com conceito Qualis A e B é baixo em relação ao que é produzido em outras áreas.

A Diplomática Contemporânea é essencial atualmente. O profissional da área necessita ter acesso em sua graduação conhecimentos mínimos obrigatórios relacionados à autenticidade e veracidade dos documentos, pois há um grande avanço na tecnologia, responsável pelo aumento da criação de documentos em meio digital.

Nesse sentido, a inexistência de um estudo de pós-graduação completo na área de Arquivologia/Arquivística no Brasil, que englobe inclusive Dou- torado e Pós-doutorado, pode ser a explicação para o não aprofundamento das discussões em torno da Diplomática Contemporânea e de tantas outras novas temáticas da área, já que não há a fidelização do estudante a um só tema ao longo de sua formação. A falta de verticalização na área resulta em um conhecimento raso e superficial, bem como na impossibilidade da publicação de textos aprofundados sobre determinadas temáticas. Tendo isso em vista, é possível afirmar que as raras publicações em Diplomática Contemporânea em revistas com Qualis A e B são apenas um reflexo da realidade de toda a estrutura de pesquisa na área.

A presença de 16 cursos de graduação no país é uma importante conquista, não sendo suficiente, entretanto, para a consolidação da área. Por essa razão, defende-se a criação de uma pósgraduação completa em Arquivologia no Brasil, a fim de gerar um círculo virtuoso em que os estudos fortaleçam as publicações em revistas científicas e estas, por sua vez, influenciem os estudos doutorais e pós-doutorais na área. Os autores dos artigos científicos sobre a temática abordada, provavelmente, não tenham avançado em suas pesquisas, alternando sua atenção entre diferentes assuntos, devido à falta de cursos de pós-graduação em diferentes áreas nas quais o aluno poderia seguir e aprofundar-se somente no que realmente fosse de seu interesse.

\section{Referências}

BOMFÁ,Cláudia Regina Ziliotto; BLATTMANN, Ursula. Acesso livre aos periódicos científicos eletrônicos: possibilidades e limitações. Disponível em: < http://www.ced.ufsc.br/ ursula/papers/claudia_ursula_castro. pdf $>$. Acesso em 16 jun. 2013. 
BRASIL. Decreto-Lei n. ${ }^{\circ} 29.741$, de 11 de julho de 1951. Institui uma Comissão para promover a Campanha Nacional de Aperfeiçoamento de pessoal de nível superior. Disponível em:< http://www2.camara.leg.br/legin/fed/ decret/1950-1959/decreto-29741-11-julho-1951-336144-publicacaooriginal1-pe.html>. Acesso em 11 out. 2016.

CARUCCI, Paola. II Documento contemporâneo: e criteri di edizione. Roma, Itália: La Nouva Itália, 1987.

CONSTANTE, Sônia Elisabete. (Coord.). A Revisão curricular do curso de Arquivologia da UFSM. In: Caderno de avaliação institucional em revista 3. Santa Maria, RS: UFSM, 2012.

GUIMARÃES, José Augusto Chaves; TOGNOLI, Nátalia Bolfarini. O papel teórico de Luciana Duranti na Diplomática Contemporânea elementos para uma reflexão sobre a organização da informação. Disponível em: $<$ www.asixarchicl/docs/100> Acesso em: 03 ago. 2009.

LUNARDELLI, Rosane Suely Alves. Arquivologia: produções em ensino e pesquisa. Londrina, PR: EDUEL, 2013.

NASCIMENTO, Lúcia Maria Barbosa do. Análise documental e análise Diplomática: perspectivas de interlocução de procedimentos, 2009. Disponível em: $<$ http://www.marilia.unesp.br/Home/ PosGraduacao/CienciadaInformacao/ Dissertacoes/nascimento $1 \mathrm{mb}$ do mar. pdf $>$. Acesso em: 24 maio $201 \overline{3}$.

RICHTER, Eneida I. S.; GARCIA Olga M. C.; PENNA, Elenita F. Introdução à Arquivologia. Santa Maria, RS: Universidade Federal de Santa Maria, 1997.

RODRIGUES, Ana Célia. Diplomática contemporânea como fundamento metodológico da identificação de tipologia documental em arquivos. 2012. Disponível em: < http://enancib. ibict.br/index.php/enancib/xenancib/ paper/viewFile/3161/2287>. Acesso em: 11 out. 2016.
RODRIGUES, Ana Célia. Da abordagem clássica da diplomática a moderna tipologia: a trajetória de um referencial metodológico para a identificação de documentos de arquivo. In: RICHTER, Eneida Schirmer. Paleografia e Diplomática no curso de Arquivologia. Santa Maria, RS: UFSM, 2007.

VIANA, Claudio Muniz; RODRIGUES, Ana Célia. Diplomática Contemporânea como metodologia para organização de arquivos de arquitetura. In: II Reunião Brasileira de Ensino e Pesquisa em Arquivologia (Reparq). Rio de Janeiro, 2011. Disponível em: < https://docs.google.com/a/ arquivistica.org/viewer? $\mathrm{a}=\mathrm{v} \& \mathrm{pid}=\mathrm{si}$ tes\&srcid=YXJXdW12aXN0aWNhLm9yZ3xyZXBhenF8Z3g6NWEzOWUzYmU5NTk5OTRmYw $>$ Acesso em: 10 mar. 2013. 